\title{
Nutrients Extracted from Chicken Manure Accelerate Growth of Microalga Scenedesmus obliquus HTB1
}

\author{
Xiaotian Han ${ }^{1,2,3}$, Nicole Rusconi1, Pervaiz Ali' ${ }^{1}$, Kevin Pagkatipunan ${ }^{1}$, Feng Chen ${ }^{1 *}$ \\ ${ }^{1}$ Institute of Marine and Environmental Technology, University of Maryland Center for Environmental Science, Baltimore, \\ MD, USA \\ ${ }^{2}$ CAS Key Laboratory of Marine Ecology and Environmental Science, Institute of Oceanography, Chinese Academy of Sciences, \\ Qingdao, China \\ ${ }^{3}$ College of Marine Life Sciences, Ocean University of China, Qingdao, China \\ Email:*chenf@umces.edu
}

How to cite this paper: Han, X.T., Rusconi, N., Ali, P., Pagkatipunan, K. and Chen, F. (2017) Nutrients Extracted from Chicken Manure Accelerate Growth of Microalga Scenedesmus obliquus HTB1. Green and Sustainable Chemistry, 7, 101-113. https://doi.org/10.4236/gsc.2017.72009

Received: March 22, 2017

Accepted: May 15, 2017

Published: May 18, 2017

Copyright (C) 2017 by authors and Scientific Research Publishing Inc. This work is licensed under the Creative Commons Attribution International License (CC BY 4.0).

http://creativecommons.org/licenses/by/4.0/

\begin{abstract}
Sustainable development using wastes as resources is a new paradigm. Chicken manure contains rich amounts of nitrogen and phosphorus and has been used as crop fertilizer. However, little is known about whether nutrients of chicken manure are suitable and efficient to support the rapid growth of microalgae. In this study, we explore the possibility of using nutrient extracted from chicken manure to grow microalgae. We used an algal strain Scenedesmus sp. $\mathrm{HTB} 1$, which is an oleaginous species with high $\mathrm{CO}_{2}$ tolerance capability. The growth performance of HTB1 on various media amended with nutrient extracted from three different chicken manure sources was monitored and compared to the growth rate of HTB1 grown in the standard medium BG11. Meanwhile, the changes of total nitrogen $(\mathrm{N})$ and phosphorus $(\mathrm{P})$, both organic and inorganic, were measured during the growth period. Culture media enriched with the nutrient extracted from two chicken manure sources outperformed the standard culture medium BG11 in terms of algal biomass production. When cultivated with manure nutrient, HTB1 utilized inorganic $\mathrm{N}$ efficiently, but consumed very little organic $\mathrm{N}$ during the experimental growth period. However, HTB1 was able to utilize both organic and inorganic phosphorus. We demonstrate that nutrient extracted from chicken manure support rapid growth and high biomass yield in microalgae Scenedesmus obliquus HTB1. Therefore chicken manure holds great promise to be used as a cost-effective and efficient fertilizer for large-scale production of microalgae.
\end{abstract}

\section{Keywords}

Microalgae, Scenedesmus, Chicken Manure, Nutrient Recycle 


\section{Introduction}

Microalgae can be used for bioenergy, human nutrition, livestock feed, cosmetics, pharmaceuticals and production of chemicals [1] [2] [3] [4]. They consume carbon dioxide in the atmosphere through photosynthesis, reducing the negative environmental impact caused by excess carbon dioxide [5] [6] [7].

The advantages of using algae over land plants in biodiesel production include higher productivities and no requirement of agricultural land for biomass productions. Certain algal species grow quickly and are able to accumulate large quantities of triglycerides (TAGs), and these algal strains have the potential to be used for producing algal-based biodiesel [8] [9] [10].

In order to produce a large quantity of microalgae for biofuel production, a significant amount of commercial fertilizers (consisting of mainly nitrogen and phosphorus) are required. Expenditure on fertilizers for growing algae in large systems is one of the major factors that contribute to the current high cost of algal-based biofuels [11]. Moreover, the production of commercial fertilizers generates a significant amount of $\mathrm{CO}_{2}$ pollution contributing in global warming [12].

Clearly, massive production of microalgae can benefit greatly from a more economical and sustainable nutrient resource. Chicken manure can be a waste product but a resource, if used wisely. It is rich in ammonia, phosphate, and potassium, and also contains substantial amounts of trace elements such as $\mathrm{Fe}, \mathrm{Mg}$, $\mathrm{Mn}, \mathrm{S}$, and $\mathrm{Zn}$, which are all essential for growing algae [13] [14] [15].

Rapid growth of the poultry industry has raised concerns about the disposal of poultry wastes. It has been reported that the US produces more than 10 million tons of poultry litter per year [16]. The runoff coming from these chicken farms is detrimental to the environment and causes eutrophication, resulting in algal blooms and hypoxic conditions in aquatic ecosystems. These underlying signs further support the notion that chicken manure can be utilized as an economical substitute for commercial fertilizer. Additionally, the removal of excess chicken manure would neutralize hypoxic conditions that are harmful to many economically important species in the water bodies [17].

Municipal, agro-industrial, and industrial wastewater also contain significant quantities of nitrogen and phosphorus. In fact, the algal strain $S$. obliquus was found to be able to thrive in industrial waste, growing at a comparable rate to growth in a standard growth medium [18]. Poultry manure digestate supports strong growth of the microalga Chlorella vulgaris and also enhances the lipid content in $C$. vulgaris [19]. Dry chicken manure supplemented with urea has been used to grow the 'blue green algae', cyanobacteria Spirulina platensis [20]. S. obliquus, a freshwater microalga, is a candidate strain suitable for biofuel development [21] and can grow in various wastewaters [22] [23]. Recently, a new strain of $S$. obliquus HTB1 (original strain E2A), isolated from the Chesapeake Bay tributary, is able to grow under high $\mathrm{CO}_{2}$ concentration [24]. Among the many uses, mitigation of greenhouse gases using microalgae is exciting and promising. Therefore large-scale cultivation of algae will undoubtedly increase 
demand for fertilizers.

In this study, we tested the growth performance of HTB1 in different chicken manure media and monitored the uptake of nutrients during the growth period. We found that algal strain HTB1 grows rapidly in chicken manure media. Surprisingly, two types of chicken manure media resulted in higher algal biomass than the standard medium BG11.

\section{Materials and Methods}

\subsection{Microalgae and Culture Media}

S. obliquus HTB1 is an algal strain isolated from the upper Chesapeake Bay (Back River), and maintained in our laboratory in Institute of Marine and Environmental Technology (IMET), at the University of Maryland Center for Environmental Science. Strain HTB1 is a fast growing alga that can thrive in high levels of $\mathrm{CO}_{2}$ [24]. HTB1 is able to grow in large photobioreactors charged with flue gas from a power plant. Therefore, HTB1 was used as a candidate strain in this experiment. To evaluate the growth of HTB1 in the culture media amended with various manure nutrients, four kinds of culture media were prepared: 1) BG11, a standard culture medium for freshwater microalgae (to serve as a reference); 2) CM, a culture medium amended with nutrient extracted from manufactured chicken manure (Chickity Doo-Doo); 3) RA, a culture medium amended with nutrient extracted from dry raw chicken manure collected from the Hayfields Farm, Howard County, Maryland; 4) RB, a culture medium amended with nutrient extracted from wet chicken manure collected from the Way Back Farm, Howard County, Maryland. To prepare each chicken manure nutrient extract, 200 grams of chicken manure was mixed into $1 \mathrm{~L}$ of $\mathrm{dH}_{2} \mathrm{O}$ in a beaker, then stirred vigorously 3 times and stored overnight at $4^{\circ} \mathrm{C}$ in a refrigerator. Supernatant was then collected and filtered through a $20 \mu \mathrm{m}$ pore size mesh, and stored as a nutrient stock in a sealed bottle at $4^{\circ} \mathrm{C}$. The CM, RA, and RB media were prepared at a 1:10 ratio with the respective chicken manure stock and tap water. BG11 was prepared using the recipe provided by The National Center for Marine Algae and Microbiota.

\subsection{Culturing Conditions}

HTB1 cultures $(600 \mathrm{ml})$ were grown in $1 \mathrm{~L}$ Erlenmeyer flasks aerated with 5\% $\mathrm{CO}_{2}$ for $8 \mathrm{hrs}$ during the day, and bubbled with air for the remaining $16 \mathrm{hrs}$. After day 4 , all the flasks were aerated with $5 \% \mathrm{CO}_{2}$ continuously. Light intensity was adjusted based on the culture density: $180,360,540$ and $720 \mu \mathrm{E} \cdot \mathrm{m}^{-2} \cdot \mathrm{s}^{-1}$ for day 1, 2, 3 and days $4-7$, respectively. For each nutrient treatment, duplicate flasks were monitored. All the cultures were grown at $30^{\circ} \mathrm{C}$. Air flow rate was kept constant at $6 \mathrm{~L}$ air/min. Optical density $\left(\mathrm{OD}_{650}\right)$ was measured on daily basis. Specific growth rate was calculated from the logarithmic change of $\mathrm{OD}_{650}$ using the equation $\mu=\ln \left(N_{1} / N_{0}\right) /\left(t_{1}-t_{0}\right)$, where $\mu$ is the specific growth rate, $N_{1}$ and $N_{0}$ are the cell density $\left(\mathrm{OD}_{650}\right)$ at the time $t_{1}$ and $t_{0}$, respectively. 


\subsection{Dry Weight}

Dry weight was obtained at 48,96 and 168 hours of growth. A $50 \mathrm{ml}$ subsample was taken from each culture and centrifuged at $6,000 \mathrm{rpm}$ for $10 \mathrm{~min}$. The supernatant was used for nutrient analysis and the pellets were freeze-dried with a Labconco Freezone 2.5 lyophilizer overnight. Dry pellets were weighed to estimate the dry weight of algae.

\section{Nutrient Measurement}

Ammonium, nitrite, and phosphate were measured using Dionex Flow Injection nutrient analyzer. Total dissolved nitrogen (TDN) and total dissolved phosphorus (TDP) were measured in the Analytical Laboratory at University of Maryland Center for Environmental Science. Dissolved organic nitrogen (DON) and dissolved organic phosphorus $(\mathrm{DOP})$ were calculated by $\mathrm{DON}=\mathrm{TDN}-\left(\mathrm{NO}_{3}^{-}\right.$ $+\mathrm{NO}_{2}^{-}+\mathrm{NH}_{4}^{+}$) and DOP $=\mathrm{TDP}-\mathrm{PO}_{4}^{-3}$.

\section{Results}

\subsection{Growth Performance of HTB1 in Culture Media with Different Manure Nutrient Sources}

In one week (168 h), HTB1 grown in the CM manure medium yielded the highest dry biomass content (10.2 g. $\left.\mathrm{L}^{-1}\right)$, and the second highest dry biomass (9.3 $\mathrm{g} \cdot \mathrm{L}^{-1}$ ) was achieved in the RB manure medium (Figure 1). The standard culture medium BG11 yielded the third highest dry biomass $\left(8.0 \mathrm{~g} \cdot \mathrm{L}^{-1}\right)$. Algal dry biomass $\left(5.0 \mathrm{~g} \cdot \mathrm{L}^{-1}\right)$ was the lowest in RA manure medium. The growth curves show a similar growth trend for HTB1 in the manure media CM, RB, and standard

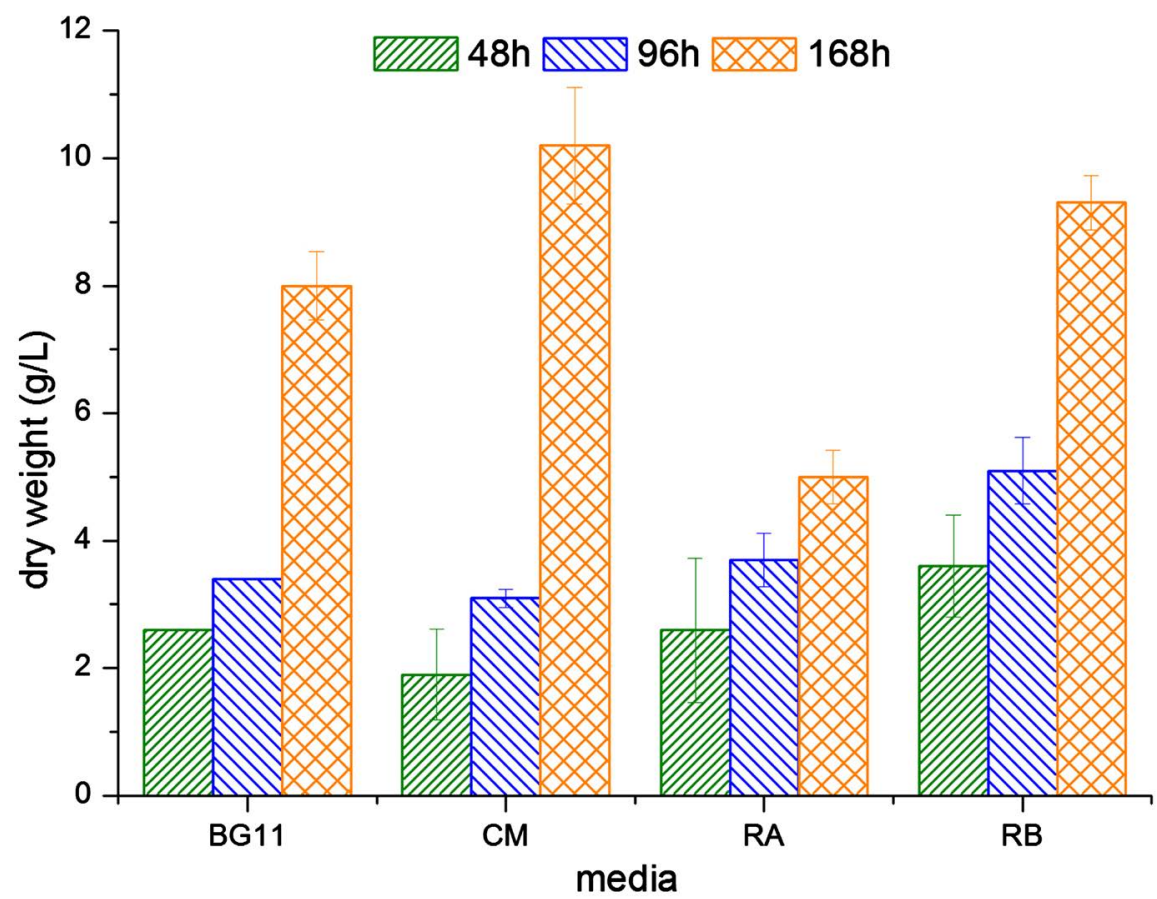

Figure 1. Dry weight of HTB1 grown in four different culture media (BG11, CM, RA and $\mathrm{RB})$. 
medium BG11 (Figure 2). At day 7, $\mathrm{OD}_{650}$ in BG11, manure media CM, RA, and $\mathrm{RB}$ were 3.32, 3.37, 2.20, and 3.14, respectively. The highest biomass of HTB1 grown in manure medium $\mathrm{CM}$ is consistent with the highest optical density $\left(\mathrm{OD}_{650}\right)$ observed in this manure medium. The specific growth rates of HTB1 grown in the manure media CM, RA, RB, and BG11 were $0.31,0.23,0.29$ and 0.32 day $^{-1}$, respectively. The highest growth rate of HTB1 in BG11 was attributed to the lower $\mathrm{OD}_{650}$ value at day 1 . We demonstrated that two of the three manure media tested in this experiment yielded higher HTB1 dry biomass compared to BG11. This experiment showed that although growth efficiency varied with the different types of manure, nutrient extract from chicken manure can support the rapid growth and high biomass of $\mathcal{S}$. obliquus $\mathrm{HTB1}$.

\subsection{Variation of Nitrogen and Phosphorus in the Culture Media}

To better understand the nutrient variation during the growth period, total nitrogen $(\mathrm{N})$ and phosphorus $(\mathrm{P})$ and dissolved inorganic and organic $\mathrm{N}$ and $\mathrm{P}$ were monitored. Ammonium $\left(\mathrm{NH}_{4}^{+}\right)$was the major DIN in all the manure media. Nitrate and nitrite were present at negligible level (data not shown). Manure medium $\mathrm{CM}$ contained total $\mathrm{N}$ twice as manure media RA and RB (Figure 3). In $\mathrm{CM}$, dissolved inorganic nitrogen (DIN) and dissolved organic nitrogen (DON) were nearly equal at the beginning of experiment (Figure 3(i)). At the starting point, CM contained $35 \mathrm{mg} \cdot \mathrm{L}^{-1}$ ammonium. HTB1 depleted DIN (ammonium) by day 4 , and it appears that HTB1 did not utilize the bulk of DON by day 7 (Figure 3(i)). At the starting point, manure media RA and RB had similar

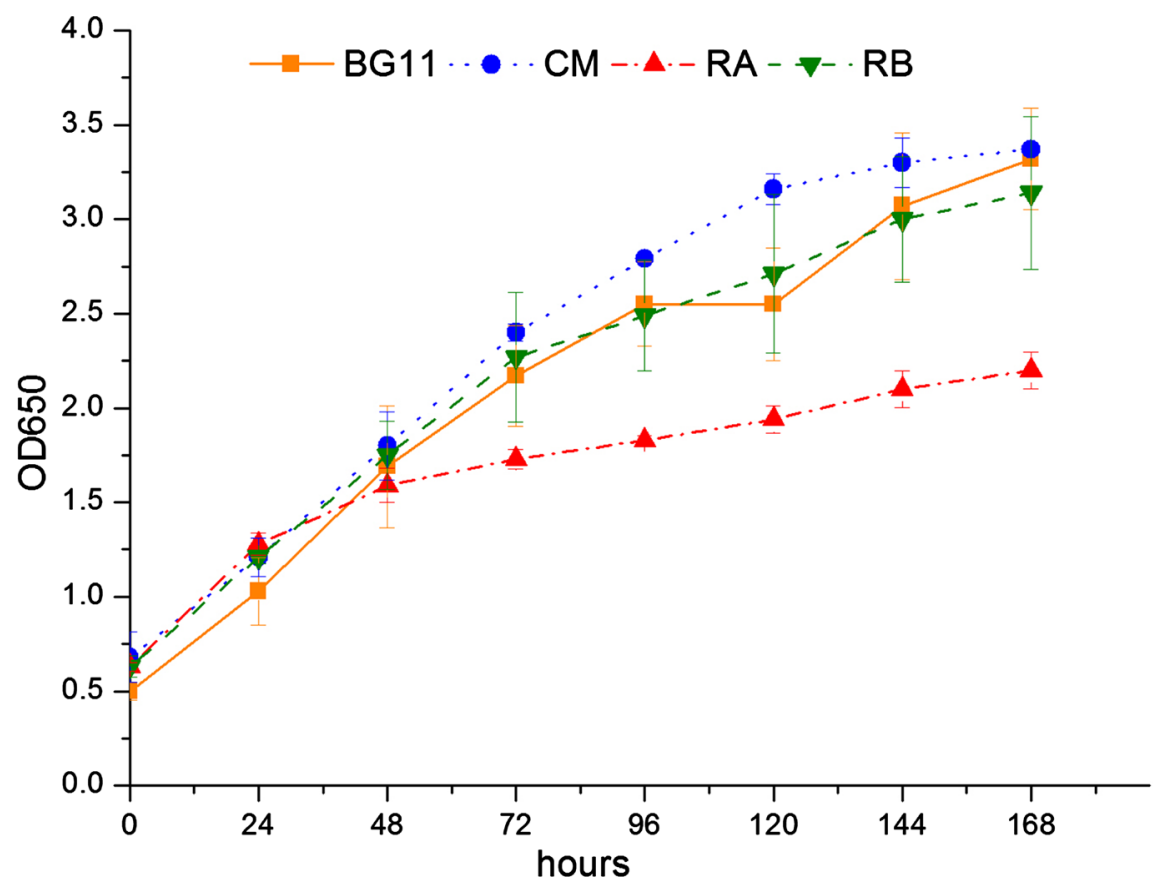

Figure 2. Growth curves of HTB1 in different culture media. BG11: a standard medium used for growing freshwater algae; CM: Chickity Doo Doo brand fertilizer; RA: Raw chicken manure taken from the Hayfield Farm; RB: Raw chicken manure taken from the Way Back Farm. 


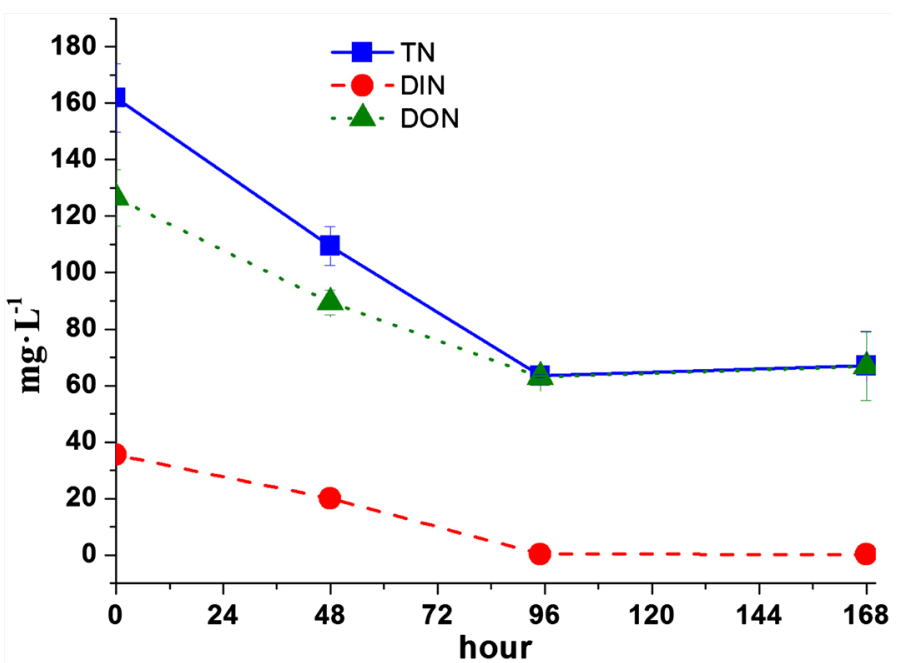

(i)

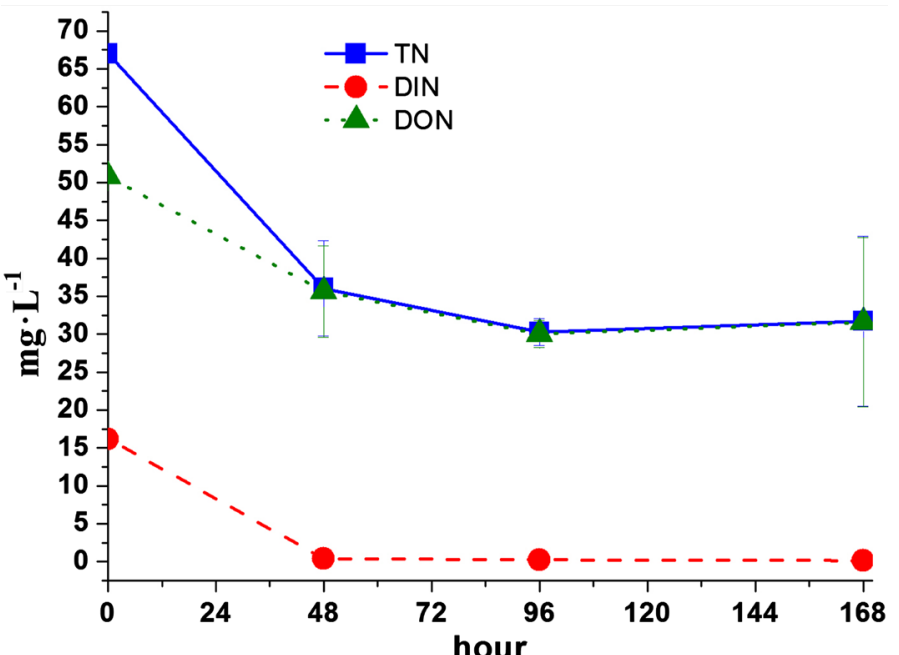

(ii)

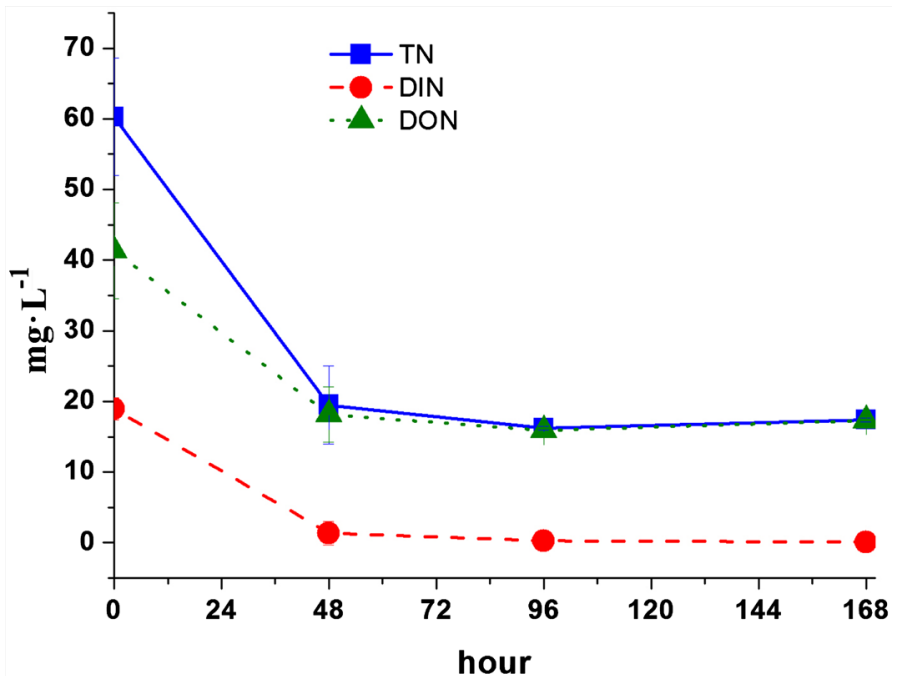

(iii)

Figure 3. Variation of total nitrogen (TN), dissolved inorganic nitrogen (DIN) and dissolved organic nitrogen (DON) for HTB1 grown in three different culture media enriched with nutrients extracted from three different sources of chicken manure: (i) CM, (ii) RA and (iii) RB. 
concentrations of ammonium (16 and $18 \mathrm{mg} \cdot \mathrm{L}^{-1}$, respectively); HTB1 quickly utilized DIN (ammonium) by day 2 in both media (Figure 3(ii) and Figure 3(iii)). Similarly, HTB1 did not appear to utilize DON in both RA and RB media.

Among all the three manure media, concentration of dissolved inorganic phosphorus (DIP) was higher than that of dissolved organic phosphorous (DOP) (Figure 4). At the beginning of experiment, the concentrations of DIP (phosphate) in CM, RA and RB were $6.2,10.8$, and $3.5 \mathrm{mg} \cdot \mathrm{L}^{-1}$, respectively. DIP was slowly depleted by day 7 in all three treatments (Figure 4). Interestingly, the concentration of DOP in all manure cultures slowly increased to a peak at day 4 , and then decreased to its lowest point at day 7 (Figures 4(i)-4(iii)). These results suggest that HTB1 can utilize both DIP and DOP in the manure nutrients. It is not clear what contributed to the increase of total dissolved phosphorus at day 4 . We could not rule out the possibility of a dilution error occurred at the analytical center as such a trend exists in all three manure samples at day 4.

Medium BG11 only uses inorganic $\mathrm{N}$ and $\mathrm{P}$; specifically, it uses $\mathrm{NaNO}_{3}$ and $\mathrm{K}_{2} \mathrm{HPO}_{4}$. BG11 does not fit in the nutrient comparison with the three manure media where different types of $\mathrm{N}$ and $\mathrm{P}$ were measured. However, the concentrations of $\mathrm{NaNO}_{3}$ and $\mathrm{K}_{2} \mathrm{HPO}_{4}$ are high in BG11 (1.5 g. $\mathrm{L}^{-1}$ and $40 \mathrm{mg} \cdot \mathrm{L}^{-1}$, respectively). It is reasonable to believe that BG11 contains more available $\mathrm{N}$ and $\mathrm{P}$ nutrients than the manure media at the beginning of the experiment. It can therefore sustain algal growth for a longer time compared to the manure media. We had to stop the experiment at day 7 as algal growth was thick, sticky and started pasting on the vessel walls.

The ratio of total nitrogen to total phosphorus varied during the growth period (Figure 5). High N/P ratios were observed at day 7 in all three types of manure, and such a trend was caused by the utilization of DIN, DIP and DOP, and the persistence of DON in the manure media.

\section{Discussion}

Increased energy crises, global warming and climate changes make microalgae a promising renewable and alternative energy feedstock. But high cost associated with algal production is the main hindrance in scale up of this process. Thus cheap sources of nutrients are essential to make it economically viable.

Our results clearly demonstrate that HTB1 can efficiently utilize the available nitrogen and phosphorus in the manure nutrient to support a high growth rate and biomass production. HTB1 reached $9-10 \mathrm{~g} \cdot \mathrm{L}^{-1}$ dry weight biomass in the two manure nutrients (CM and $\mathrm{RB}$ ) in one week. We believe that several factors contribute to such a high biomass production: 1) HTB1 is a fast growing algal strain which also thrives under high $\mathrm{CO}_{2}$ concentration [24]; 2) Bubbling with $5 \% \mathrm{CO}_{2}$ kept the $\mathrm{pH}$ between 6.8 and 7.8 in the manure media throughout the experiment; 3) Increase in light intensity with culture density improves the photosynthesis efficiency; 4) Inoculation of sufficient HTB1 culture $\left(\mathrm{OD}_{650} \approx 0.65\right)$ at the beginning of the experiment enables the algal cells to reach high cell density 


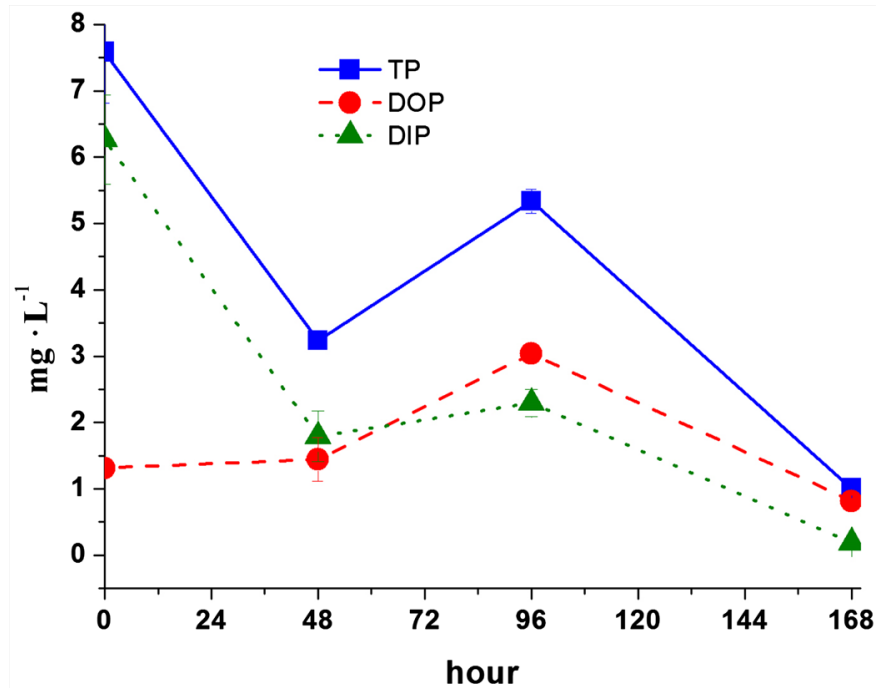

(i)

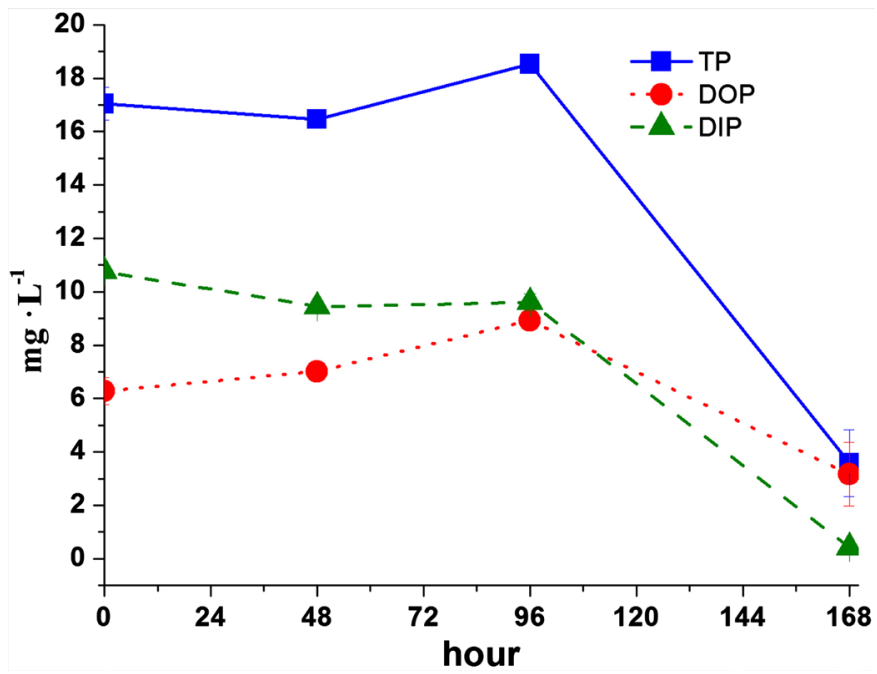

(ii)

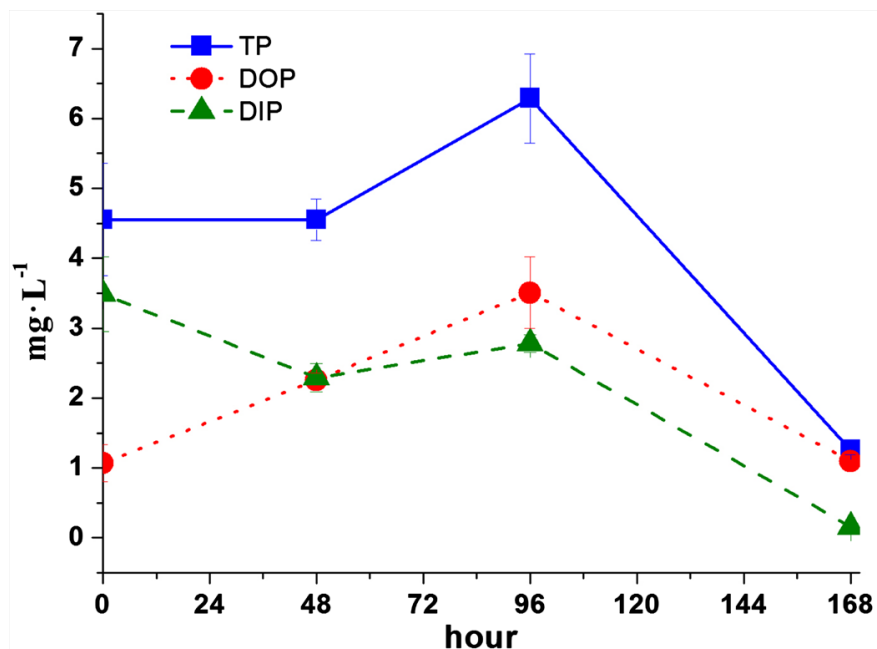

(iii)

Figure 4. Variation of total phosphorus (TP), dissolved inorganic phosphorus (DIP) and dissolved organic phosphorus (DOP) for HTB1 grown in three different culture media enriched with nutrients extracted from three different sources of chicken manure: (i) CM, (ii) RA and (iii) RB. 


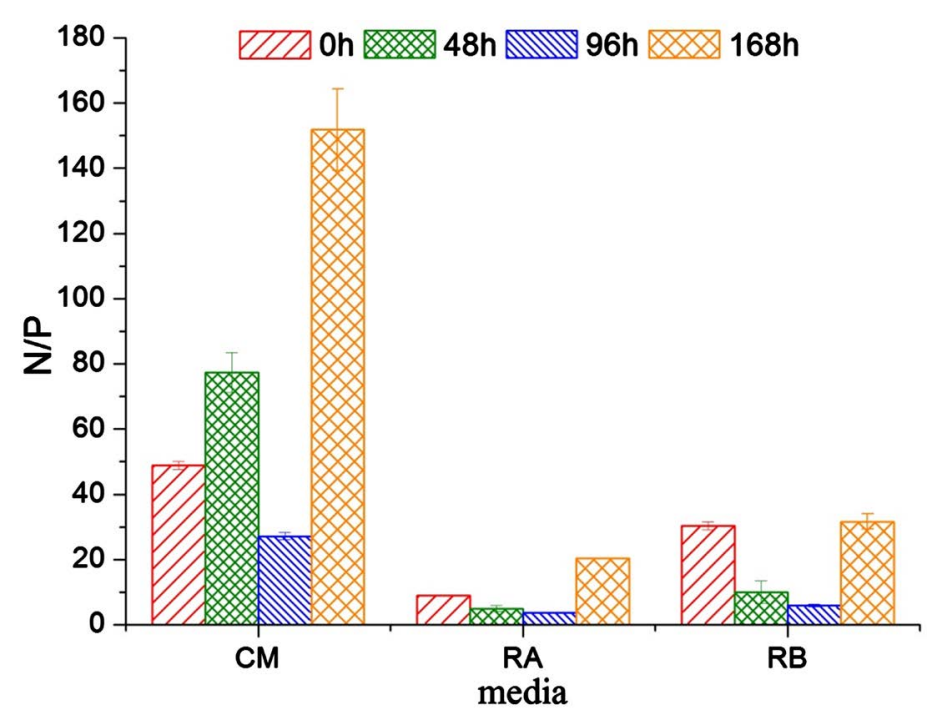

Figure 5. Variation of N/P ratio (based on molar concentration) in the culture media enriched with different nutrients extracted from three different sources of chicken manure.

in a short period. The final dry biomass in BG11 was also lower than the biomass in $\mathrm{CM}$ and $\mathrm{RB}$. The initial differences in $\mathrm{OD}$ value were very likely due to the color of the manure, as proved by a separate experiment which combined similarly filtered manure with algae and found that the OD value immediately raised $0.1-0.2$ greater than the same amount of algae in BG11 (data not shown). However, the high biomass of algae in $\mathrm{CM}$ and $\mathrm{RB}$ is the best indicator that algae did grow better in the two manure media than BG11. HTB1 grew poorly in manure medium RA. RA contains much higher total phosphorus, which may skew the optimal $\mathrm{N}$ to $\mathrm{P}$ ratio.

In a recent study effluent from chicken manure biogas plant was used as a sole nutrient source to cultivate Scenedesmus sp. AARL G022 for the production of lipids. It was observed that this algal strain demonstrated highest growth and lipid production when $25 \%$ of non-filtered effluent was used from the chicken manure biogas plant [25]. In a similar study raw poultry litter was used as a nutrient source for the cultivation of microalgae $C$. vulgaris [26]. They found that C. vulgaris grew well in the poultry litter based medium and biomass production was higher than in the control medium (BG-11). They also observed that the biomass composition of this algal sp. in poultry litter medium had higher carbohydrate and lipid content than in the control medium (BG11).

Chicken litter is a rich source of nitrogen and phosphorus. In the three tested chicken manures, DIN (mainly ammonium) only makes up $20 \%-30 \%$ of total dissolved nitrogen, and the vast majority of nitrogen source is in the DON form. Depending on the initial concentration, DIN can be used up by HTB1 within 2 4 days. However, HTB1 does not appear to utilize much of manure DON in this experiment. Although the composition of DON is not known, we suspect that manure DON is complex and may require further microbial decomposition before it can be taken up as a useful nitrogen source by HTB1. If manure DON 
remains unused by algae or co-existing bacteria over an extensive cultivation period (i.e. months), it will accumulate when a new batch of manure medium is supplied. If this is the case, the effect of accumulated DON in the culture system needs to be evaluated. DIP makes up the bulk of dissolved phosphorus in all three tested chicken manures. HTB1 is able to use both DIP and DOP for their growth, but it prefers DIP over DOP. Although chicken litter in the solid phase can be applied directly to soil to fertile plants or crops, only the extracted or dissolved nutrients from the litter can be used for algal cultures. While HTB1 has been successfully cultivated in industrial scale photobioreactors, this is the first study to lay the foundation to test the use of extracted manure nutrient in photobioreactors.

In order to produce sufficient algal biomass at the industrial level, a large amount of fertilizer is needed. The cost of fertilizer is a major economical burden for large-scale production of algae. In addition, replacing commercial fertilizer with poultry litter is environmentally benign because manufacturing chemical fertilizer emits substantial amount of green house gas. If chicken litter can replace chemical fertilizers, algal companies could save money that would otherwise be spent on commercial fertilizers. How much can it save? According to the Farm Futures report in March 2017, the retail prices for 1 ton of ammonia and phosphate fertilizer are $\$ 495$ and $\$ 486$, respectively [27]. It has been estimated that one ton of poultry litter has $\$ 80$ computed fertilizer value [16]. In the laboratory study, we used $20 \mathrm{~g}$ chicken manure to grow $1 \mathrm{~L}$ of algal culture. If one needs to set up a large raceway or large photobioreactor to grow algae, the cultivation volume will increase dramatically. One full size raceway or large photobioreactor can hold 10,000 L of algal culture, which will require $200 \mathrm{~kg}$ chicken manure to support the algal growth for one week. For one year, $52 \mathrm{nu}-$ trient reloads will be needed ( 360 days/7 days) for each culture system. Therefore, a total of 10.4 tons (52 loads $\times 200 \mathrm{~kg}$ ) chicken manure will be needed to support the algal growth in one large algal cultivation system per year. This is a saving of $\$ 832$ on fertilizer (10.4 tons $\times \$ 80$ per ton) per year for growing algae in an industrial size cultivation system.

Despite the pros mentioned above, the cons exist when applying chicken manure as an alternative fertilizer. The current price of poultry litter ranges from $\$ 10$ to $\$ 55$ per ton [16]. The transportation cost varies with the distance between poultry farm and destination. For growing algae, extraction of nutrient from poultry litter in the liquid form demands extra labor. Natural decomposition of manure can also result in the release of greenhouse gases and odors, which can make usage of manure, especially in highly populated areas, a less publicly favorable option [12]. It is beyond the scope for this study to address these issues; however, these complications need to be addressed further before use of manure on a large scale can reach its full potential for cost, environment-friendly, and practical efficiency.

Nevertheless photosynthetic microalgae uses $\mathrm{CO}_{2}$ from the flue gases and used for the production of biofuels. This results in reduced emission of GHG and also 
a renewable energy alternative, replacing the traditional fossil fuels [5]. And we demonstrated that chicken manure nutrients support vigorous algal growth thus reduce the cost associated with culturing microalgae on large scale.

\section{Conclusion}

This study for the first time demonstrates that nutrients extracted from chicken manure contain sufficient nitrogen and phosphorus to support fast growth and high biomass production for microalga HTB1. Algal strain HTB1 is able to take up ammonium, phosphate and dissolved organic phosphorus rapidly, but does not seem to incorporate dissolved organic nitrogen. This study is focused on $S$. obliquus HTB1 because HTB1 is a well-sorted strain that has been used to sequester $\mathrm{CO}_{2}$ in large photobioreactors. In future, additional algal strains can be tested to gain a better understanding of utilization of manure nutrient by diverse algal species. Nutrient extraction from chicken manure and growing microalgae to mitigate greenhouse gases is a promising technology to protect ecosystem and climate change.

\section{Acknowledgements}

We acknowledge the funding supports (NoA\#4701, NoA\#5214, and NoA\#5417) from Maryland Industrial Partnership Program, the Maryland Department of Natural Resource, HY-TEK Bio, LLC, Aoshan Science and technology innovation project (Grant No. 2016ASKJ02-1) and Marine renewable energy fund project (Grant No. GHME2001SW02). We also thank Robert Mroz and Jack French for providing chicken manure samples.

\section{Conflict of Interest}

The authors declare that they have no conflict of interest.

\section{References}

[1] Cuellar-Bermudez, S.P., Aguilar-Hernandez, I., Cardenas-Chavez, D.L., OrnelasSoto, N., Romero-Ogawa, M.A. and Parra-Saldivar, R. (2014) Extraction and Purification of High-Value Metabolites from Microalgae: Essential Lipids, Astaxanthin and Phycobiliproteins. Microbial Biotechnology, 8, 190-209. https://doi.org/10.1111/1751-7915.12167

[2] Malcata, F.X. (2011) Microalgae and Biofuels: A Promising Partnership? Trends in Biotechnology, 29, 542-549. https://doi.org/10.1016/j.tibtech.2011.05.005

[3] Wang, H.D., Chen, C., Huynh, P. and Chang, J. (2015) Exploring the Potential of Using Algae in Cosmetics. Bioresource Technology, 184, 355-362.

[4] Leu, S. and Boussiba, S. (2014) Advances in the Production of High-Value Products by Microalgae. Industrial Biotechnology, 10, 169-183.

https://doi.org/10.1089/ind.2013.0039

[5] Cuellar-Bermudez, S.P., Garcia-Perez, J.S., Rittmann, B.E. and Parra-Saldivar, R. (2015) Photosynthetic Bioenergy Utilizing $\mathrm{CO}_{2}$ : An Approach on Flue Gases Utilization for Third Generation Biofuels. Journal of Cleaner Production, 98, 53-65.

[6] Kumar, A., Ergas, S., Yuan, X., Sahu, A., Zhang, Q., Dewulf, J., Malcata, F.X. and 
ven Langenhove, H. (2010) Enhanced $\mathrm{CO}_{2}$ Fixation and Biofuel Production via Microalgae: Recent Developments and Future Directions. Trends in Biotechnology, 28, 371-380. https://doi.org/10.1016/j.tibtech.2010.04.004

[7] Klinthong, W., Yang, Y., Huang, C. and Tan, C. (2015) A Review: Microalgae and Their Applications in $\mathrm{CO}_{2}$ Capture and Renewable Energy. Aerosol and Air Quality Research, 15, 712-742. https://doi.org/10.4209/aaqr.2014.11.0299

[8] Scott, S.A., Davey, M.P., Dennis, J.S., Horst, I., Howe, C.J., Lea-Smith, D.J. and Smith, A.G. (2010) Biodiesel from Algae: Challenges and Prospects. Current Opinion in Biotechnology, 21, 277-286. https://doi.org/10.1016/j.copbio.2010.03.005

[9] Miao, X. and Wu, Q. (2006) Biodiesel Production from Heterotrophic Microalgal Oil. Bioresource Technology, 97, 841-846.

[10] Hu, Q., Sommerfeld, M., Jarvis, E., Ghirardi, M., Posewitz, M., Seibert, M. and Darzins, A. (2008) Microalgal Triacylglycerols as Feedstocks for Biofuel Production: Perspectives and Advances. The Plant Journal, 54, 621-639. https://doi.org/10.1111/j.1365-313X.2008.03492.x

[11] Mata, T.M., Melo, A.C., Meireles, S., Mendes, A.M., Martins, A.A. and Caetano, N.S. (2013) Potential of Microalgae Scenedesmus obliquus Grown in Brewery Wastewater for Biodiesel Production. Italian Association of Chemical Engineering, 32, 901-906.

[12] Moore, P.A., Daniel, T.C., Sharpley, A.N. and Wood, C.W. (1998) Chapter 3: Poultry Manure Management. In: Wright, R.J., Kemper, W.D., Millner, P.D., Power, J.F. and Korcak, R.F., Eds., Agricultural Uses of Municipal, Animal and Industrial Byproducts, 60-77.

[13] Kunikane, S., Kaneko, M. and Maehara, R. (1984) Growth and Nutrient Uptake of Green Alga, Scenedesmus Dimorphus, Under a Wide Range of Nitrogen/Phosphorus Ratio. Water Research, 18, 1299-1311.

[14] Ortiz Escobar, M.E. and Hue, N.V. (2008) Temporal Changes of Selected Chemical Properties in Three Manure-Amended Soils of Hawaii. Bioresource Technology, 99, 8649-8654.

[15] Faridullah, Irshad, M., Yamamoto, S., Honna, T. and Eneji, A.E. (2009) Characterization of Trace Elements in Chicken and Duck Litter Ash. Waste Management, 29, 265-271.

[16] Dunkley, C.S., Cunningham, D.L. and Harris, G.H. (2014) The Value of Poultry Litter in South Georgia. Extension Bulletin 1386, University of Georgia, Athens, Georgia.

[17] Stephenson, A.H., McCaskey, T.A. and Ruffin, B.G. (1990) A Survey of Broiler Litter Composition and Potential Value as a Nutrient Resource. Biological Wastes, 34, $1-9$.

[18] Toyub, M.A., Miah, M.I., Habib, M.A.B. and Rahman, M.M. (2008) Growth Performance and Nutritional Value of Scenedesmus obliquus Cultured in Different Concentrations of Sweetmeat Factory Waste Media. Bangladesh Journal of Animal Sciences, 37, 86-93.

[19] Iyovo, G.D., Du, G. and Chen, J. (2010) Poultry Manure Digestate Enhancement of Chlorella vulgaris Biomass under Mixotrophic Condition for Biofuel Production. Journal of Microbial and Biochemical Technology, 2, 51-57. https://doi.org/10.4172/1948-5948.1000023

[20] Ungsethaphand, T., Peerapornpisal, Y. and Whangchai, N. (2009) Production of Spirulina platensis Using Dry Chicken Manure Supplemented with Urea and Sodium Bicarbonate. Maejo International Journal of Science and Technology, 3, 379- 
387. http://www.mijst.mju.ac.th/vol3/379-387.pdf

[21] Miranda, J.R., Passarinho, P.C. and Gouveia, L. (2012) Bioethonol Production From Scenedesmus obliquus Sugars: The Influence of Photobioreactors and Culture Conditions on Biomass Production. Applied Microbiology and Biotechnology, 96, 555564. https://doi.org/10.1007/s00253-012-4338-Z

[22] Hodaifa, G., Martinez, M.E. and Sanchez, S. (2008) Use of Industrial Wastewater from Olive Oil Extraction for Biomass Production of Scenedesmus obliquus. Bioresource Technology, 99, 1111-1117.

[23] Li, Y. (2011) Inexpensive Culturing of Freshwater Algae in a Simulated Warm Environment Using Chicken Manure Medium. Dissertation, Chalmers University of Technology, Gothenburg.

http://studentarbeten.chalmers.se/publication/146701-inexpensive-culturing-of-fres hwater-algae-in-a-simulated-warm-environment-using-chicken-manure-mediu

[24] Liu, Z., Zhang, F. and Chen, F. (2013) High Throughput Screening of $\mathrm{CO}_{2}$-Tolerating Microalgae Using GasPak Bags. Aquatic Biosystems, 9, 23. https://doi.org/10.1186/2046-9063-9-23

[25] Duangjan, K., Kumsiri, B. and Pumas, C. (2016) Lipid Production by Microalga Scenedesmus sp. AARL G022 in the Cultivation with Effluent from Chicken Manure Biogas Plant. Desalination and Water Treatment, 57, 27191-27198. https://doi.org/10.1080/19443994.2016.1167625

[26] Markou, G., Iconomou, D. and Muylaert, K. (2016) Applying Raw Poultry Litter Leachate for the Cultivation of Arthrospira platensis and Chlorella vulgaris. Algal Research, 13, 79-84.

[27] Knorr, B. (2017) Weekly Fertilizer Review. Farm Futures. http://farmfutures.com/story-weekly-fertilizer-review-0-30765

Submit or recommend next manuscript to SCIRP and we will provide best service for you:

Accepting pre-submission inquiries through Email, Facebook, LinkedIn, Twitter, etc. A wide selection of journals (inclusive of 9 subjects, more than 200 journals)

Providing 24-hour high-quality service

User-friendly online submission system

Fair and swift peer-review system

Efficient typesetting and proofreading procedure

Display of the result of downloads and visits, as well as the number of cited articles

Maximum dissemination of your research work

Submit your manuscript at: http://papersubmission.scirp.org/

Or contact gsc@scirp.org 